\title{
The NBD-NBD interface is not the sole determinant for transport in $A B C$ transporters
}

\author{
Yaprak Dönmez ${ }^{1}$, Zahida Parveen ${ }^{2}$, Peter Chiba ${ }^{2}$, Thomas Stockner $^{1 *}$ \\ From 18th Scientific Symposium of the Austrian Pharmacological Society (APHAR). Joint meeting with the \\ Croatian, Serbian and Slovenian Pharmacological Societies. \\ Graz, Austria. 20-21 September 2012
}

\section{Background}

The ABC (ATP-binding cassette) transporter superfamily constitutes one of the largest classes of membrane transporters. ABCB1 contains two functional nucleotide binding sites (NBSs) at the interface of the two nucleotide binding domains (NBDs), whereas $\mathrm{ABCB} 11$ has one degenerate ATP binding site. According to the structural alignments, $\mathrm{ABCB} 1$ and $\mathrm{ABCB} 11$ differ by only four residues in the NBD-NBD interface, all of them located at NBS1: E556M, G1178R, Q1180E and S474E. It has been shown that a mutation of the Walker B glutamate (E556) abolishes steady-state ATP hydrolysis and drug transport activities of ABCB1 [1]. We tested the hypothesis that function may be restored in ABCB1 when NBS1 is engineered on the basis of $\mathrm{ABCB} 11$.

\section{Methods}

These four residues were mutated in $A B C B 1$ according to ABCB11. Wild-type or mutant ABCB1-transfected cells were used to measure rhodamine 123 transport by flow cytometry. First-order rate constants corresponding to efflux rate were plotted as a function of ABCB1 expression, which was determined by MRK16 staining.

\section{Results}

The E556M mutation of the catalytic glutamate resulted in loss of transport function. While the double mutation in the LSGGQ motif (G1178R, Q1180E) reduced transport to below $20 \%$, no measurable rhodamine 123 efflux was observed in either the triple mutant (E556M, G1178R, Q1180E) or the quadruple mutant (E556M, G1178R, Q1180E, S474E).

\footnotetext{
* Correspondence: thomas.stockner@meduniwien.ac.at

${ }^{1}$ Institute of Pharmacology, Center for Physiology and Pharmacology,

Medical University of Vienna, 1090 Vienna, Austria

Full list of author information is available at the end of the article
}

\section{Conclusions}

Engineering of ABCB1 NBS1 to mimic ABCB11 NBS1 yields a non-functional transporter, indicating that the NBD-NBD interface is not the sole determinant for transport in $\mathrm{ABC}$ exporters.

\section{Acknowledgements}

We thank the Austrian Science Fund (FWF) for financial support (FWF project P23319).

\section{Author details}

'Institute of Pharmacology, Center for Physiology and Pharmacology, Medical University of Vienna, 1090 Vienna, Austria. ${ }^{2}$ Institute of Medical Chemistry, Center for Pathobiochemistry and Genetics, Medical University of Vienna, 1090 Vienna, Austria.

Published: 17 September 2012

\section{Reference}

1. Sauna ZE, Müller M, Peng XH, Ambudkar SV: Importance of the conserved Walker B glutamate residues, 556 and 1201, for the completion of the catalytic cycle of ATP hydrolysis by human P-glycoprotein (ABCB1). Biochemistry 2002, 41:13989-14000.

doi:10.1186/2050-6511-13-S1-A78

Cite this article as: Dönmez et al:: The NBD-NBD interface is not the sole determinant for transport in $A B C$ transporters. BMC Pharmacology and Toxicology 2012 13(Suppl 1):A78.

Submit your next manuscript to BioMed Central and take full advantage of:

- Convenient online submission

- Thorough peer review

- No space constraints or color figure charges

- Immediate publication on acceptance

- Inclusion in PubMed, CAS, Scopus and Google Scholar

- Research which is freely available for redistribution

\section{() Biomed Central}

